\title{
COBERTURAS VERDES
}

\section{Juliana Miranda Lima}

Aluna de Arquitetura e Urbanismo no Centro Universitário Augusto Motta (UNISUAM), RJ, Brasil juliana.lima30@outlook.com

Stela Maris Rodrigues da Silva Aluna de Arquitetura e Urbanismo no Centro Universitário Augusto Motta (UNISUAM), RJ, Brasil stela_maris@outlook.com

\section{Rodrigo Costa Faustino}

Aluno de Engenharia Civil no Centro Universitário Augusto Motta (UNISUAM), RJ, Brasil Rodrigocfaustino85@gmail.com José Roberto Moreira Ribeiro Gonçalves Mestre em Engenharia Agrícola e Ambiental pela Universidade Federal Rural do Rio de Janeiro Professor do Centro Universitário Augusto Motta (UNISUAM), RJ Brasil joserobertoverde@gmail.com 
O presente artigo tem como objetivo apresentar informações relacionadas aos telhados verdes destacando os principais pontos em relação ao assunto a partir de uma extensa pesquisa bibliográfica e documental. $O$ artigo encontra-se dividido em tópicos que visam apresentar os principais pontos que devem ser observados sobre os telhados verdes como sua história, seus tipos, entre outros, com o objetivo de esclarecer mais sobre sua utilização e sua importância dentro de um contexto geral. Após o estudo, foi constatado que ainda há uma falta de investimento em pesquisas para a aplicação desta tecnologia no Brasil, embora já tenha sido comprovada de forma prática, em outros países, o seu auxilio de forma positiva na qualidade de vida e na preservação do meio ambiente.

Palavras-chave: Telhado verde; Meio ambiente; Sustentabilidade.

\begin{abstract}
The present article aims to apresent information related to green roofs highlighting the main points in relation to the subject from an extensive bibliographical and documentary research. The article is divided in topics that aim to present the main points that must be observed on the green roofs as their history, their types, among others, with the purpose of clarifying more about its use and its importance within a general context.

After the study, it was found that there is still a lack of investment in research for the application of this technology in Brazil, although it has already been proven in practice in other countries to positively assist the quality of life and the preservation of the environment.
\end{abstract}

Keywords: Green roof; Environment; Sustainability.

\title{
1 INTRODUÇÃO
}

O constante crescimento das áreas urbanas, trouxeram uma consequente dimi- 
nuição considerável nas áreas verdes trazendo grandes problemas não só para determinadas regiões, mas, também se tornaram responsáveis por mudanças climáticas a nível mundial (SANTOS et al., 2013). Atualmente, existe um maior interesse em diminuir esses impactos negativos e dentro disso começaram a surgir medidas para que começássemos a tomar atitudes mais responsáveis, principalmente em relação à construção civil, essa tida como uma das maiores responsáveis pela atual situação. Essas medidas visam uma maior conscientização de um modo geral para que possamos mitigar os impactos negativos com a adoção de novas atitudes sustentáveis com a mudança de velhos hábitos.

Uma consequência desses hábitos está relacinada principalmente ao desconforto térmico gerado pela impermeabilização da maior parte dos solos urbanos e pelos materiais de construção que acabam refletindo o calor do Sol, causando a inércia térmica acumulada por esses materiais principalmente nas coberturas das edificações causando esse desconforto (OLIVEIRA, 2016). Outro ponto negativo está ligado a poluição causada pela constante queima de combustíveis fósseis usados principalmente por automóveis, aparelhos de refrigeração dentre outros que são nocivos a saúde e ao ambiente em geral.

Há algum tempo, vem se buscando soluções que contribuam para a diminuição desses problemas, e uma dessas soluções é a utilização das coberturas ou telhados verdes, também conhecidos como "cobertura vegetal”, "jardim suspenso" ou "cobertura viva". Esse tipo de cobertura consiste na substituição das coberturas tradicionais por técnicas que utilizam jardins e gramados para cobrir as edificações, que também podem ser instalados sobre telhados convencionais dependendo da técnica a ser utilizada (HENN, 2016).

O telhado verde faz parte de um conceito denominado Naturação que envolve a arquitetura, engenharia civil e a biologia com o intuito de desenvolver a natureza em meio ao ambiente urbano e melhorar a qualidade de vida amenizando os impactos negativos de forma sustentável e viável, segundo (SILVA, 2016).

A implantação de coberturas verdes se tornou um grande aliado do meio ambiente, possibilitando diferentes formas de aplicação sobre as estruturas que proporcionam inúmeros benefícios em conjunto com outras alternativas.

Este artigo teve como objetivo enfatizar a necessidade da utilização de telhados 
verdes no contexto atual e descrever a sua importância diante da situação dos centros urbanos. Descreve-se seus tipos e as diferentes formas de implantação, analisando as vantagens e as desvantagens de seu desempenho e na contribuição em geral. Destaca-se também a necessidade de estudos científicos sobre o assunto, pois há uma carência significativa em relação ao número de artigos internacionais que vem sendo feito ao longo dos últimos anos (BÄR, 2018).

\section{HISTÓRIA DOS TELHADOS VERDES}

Os telhados verdes tiveram sua primeira aparição por volta do século $\mathrm{V}$, mais precisamente na antiga Babilônia (atual Iraque). Os Jardins Suspensos da Babilônia, como ficaram conhecidos, tiveram como seu primeiro idealizador o rei Nabucodonozor II, relatado por (CORRENT, 2017), e fora projetado para sua esposa Amitis. Nesses jardins se encontravam várias árvores frutíferas, flores tropicais, piscinas, cascatas, esculturas de deuses e até pequenos animais e ainda contavam com um eficiente sistema de irrigação.

Os jardins suspensos da Babilônia, representado na figura 1, fazem parte das sete maravilhas do mundo antigo mesmo sem a existência de provas que comprovem sua construção sendo apenas citadas em escritos gregos (CORRENT, 2017).

FIGURA 1 - Representação de um jardim suspenso da Babilônia.

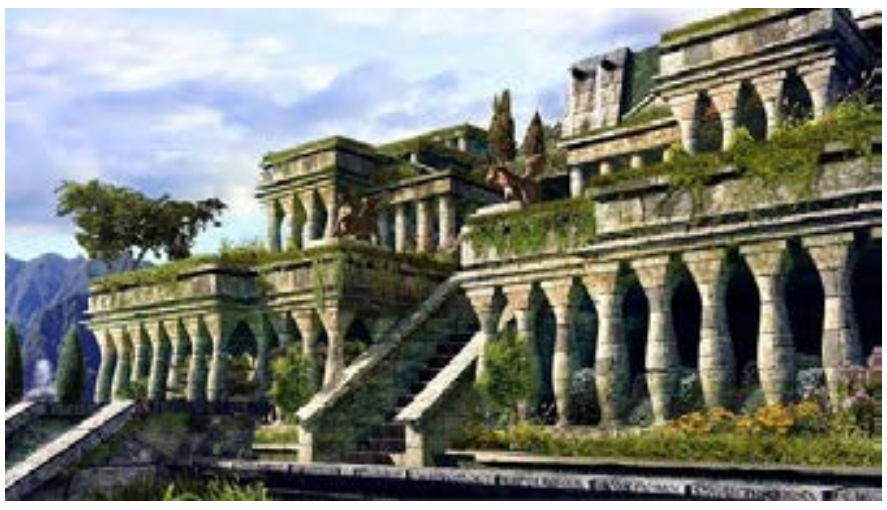

FONTE: (https://dicasarquitetura.com.br/os-jardins-suspensos-da-babilo-

nia/, 2016) 
Também há registros de que os telhados verdes foram utilizados pelos Vikings em regiões de clima frio do hemisfério Norte, mais precisamente no Canadá (ALMEIDA, 2018). Tais registros datam de cerca do ano 1000 D.C. e segundo pesquisas, as casas eram feitas de pedras e madeiras locais e possuiam telhados cobertos por vegetação gramínea, que servia como um isolante térmico natural. Até hoje essas tradições se mantém na cultura nórdica sendo os lugares que mais se destacam por seus telhados verdes na Escandinávia a Islândia, a Noruega e as ilhas Faroe (figura 2), onde existem comunidades inteiras com casebres com telhados verdes.

FIGURA 2 - Saksun Village, Ilhas Faroe.

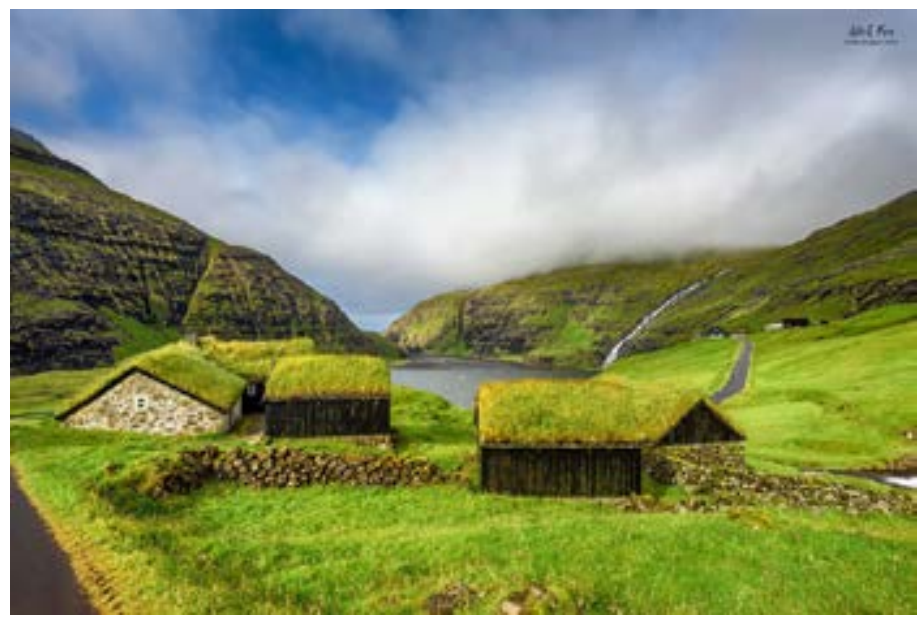

FONTE: (Foto Nick Fox- casalnomade.com, 2019)

Muito tempo depois, já na era Moderna na década de 20, com os 5 pontos da arquitetura formulados por Le Corbusier (pilotis, terraço jardim, planta livre, janela em fita e fachada livre), a utilização do telhado verde começou a se difundir com a intenção de compensar a questão ambiental sendo uma solução para as grandes cidades da época (BALDESSAR, 2012).

Influenciado pelo Movimento Modernista na década de 30, foi implantado o primeiro telhado verde no Brasil com a construção do prédio do Ministério da Educação e Saúde, no Rio de Janeiro, com a supervisão do arquiteto Le Corbusier, formando uma equipe com os arquitetos Niemeyer, Costa, Reidy, Moreira, Leão e Vasconcellos, com o jardim projetado por Burle Marx, como observado na figura 3. 
Na década de 60 os telhados verdes já eram bastante utilizados pela Europa sendo conhecidos como a "salvação verde", sendo considerados como uma solução contra a degradação do meio ambiente (RANGEL, 2015). A partir de então, com o passar dos anos houve o surgimento de novas pesquisas relacionadas ao aprimoramento das técnicas, materiais e vegetação.

Na década de 80, a Alemanha estimulada por leis municipais, estaduais e federais, subsidiavam de 35 a 40 marcos alemães por metro quadrado de cobertura construída. Hoje, segundo (SANTOS et al., 2017), a Alemanha é líder mundial em telhados verdes, onde destaca-se a cidade de Berlim e Stugart havendo incentivos em quase 1/3 das demais cidades.

FIGURA 3 - Terraço jardim do Palácio Capanema, projetado por Burle Marx.

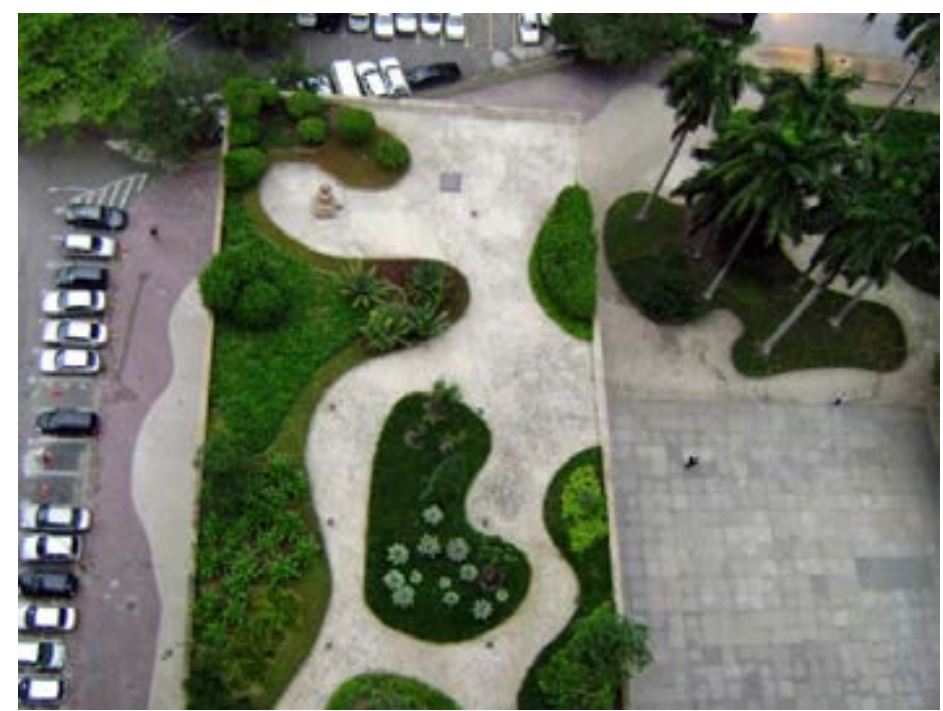

FONTE: (https://www.faculdademax.edu.br/arquitetura-telhados-verdes-garantem-beleza-e-sustentabilidade/ )

Na década de 90, houve uma tentativa por parte de fabricantes europeus na implantação dos sitemas de telhados verdes na América do Norte. Apesar do termo já ser conhecido entre os Norte americanos, houve uma grande dificuldade pela falta de informações e exemplos relacionados ao assunto e principalmente pelas diferenças culturais e políticas na qual não haviam interesse nesse tipo de investimento (CORRENT, 2017). 
Atualmente, as questões ambientais se tornaram um assunto indispensável e de grande necessidade, sendo discutidas diferentes soluções mundialmente sendo a utilização das coberturas vivas tidas como uma das mais eficientes. No Brasil, a adoção desse sistema ainda é pouco abordado em relação à residências sendo mais utilizado em edifícios comerciais, shopping centers, etc.

\section{CLASSIFICAÇÃO}

Segundo a International Green Roof Association (Igra), o telhado verde classifica-se em 3 tipos: extensivo, intensivo e semi-intensivo, exemplificado pela figura 4. Essa classificação corresponde ao tipo de vegetação existente e ao peso que cada tipo realiza sobre a estrutura.

FIGURA 4 - Ilustração esquemática dos diferentes tipos de telhados verdes.

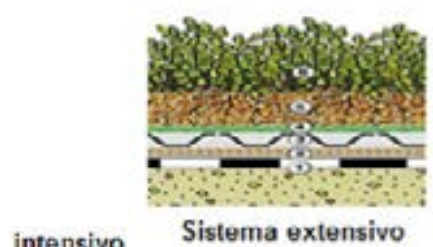

intensivo
Sistema extensivo

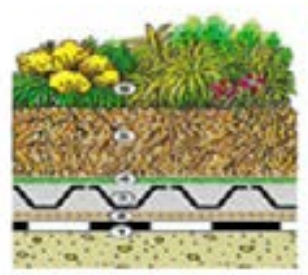

Sistema semi-extensivo

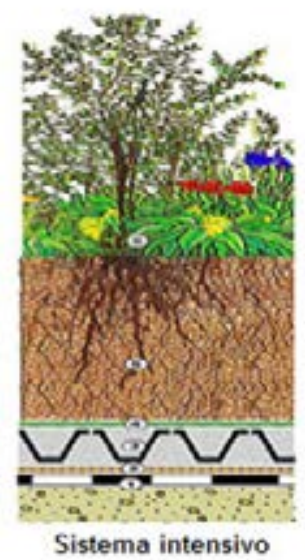

Sistema intensivo

FONTE: (Adaptado de Green Roof Service LLC, 2010)

O telhado extensivo é caracterizado pelo uso de plantas de pequeno porte e rasteiras(figura 5), como em um jardim, e é considerado o mais leve por usar uma camada mais fina de substrato que pesa em torno de 60 a $150 \mathrm{~kg} / \mathrm{m}^{2}$. Geralmente as plantas que o compõe são gramíneas e aromáticas, que não necessitam de manutenção frequente (SANTOS et al., 2017), e dependendo da construção podem ser instalados em edificações 
sem alterações estruturais. É o tipo de cobertura que necessita da menor frequencia de manutençao sendo recomendadas apenas uma vez por ano.

FIGURA 5 - Cobertura verde extensiva em telhado inclinado.

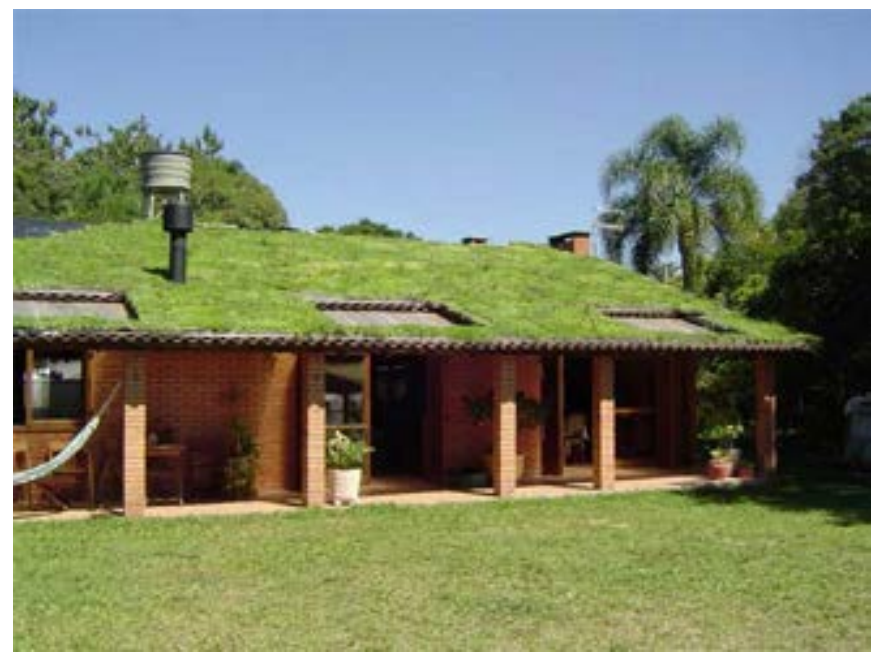

FONTE: (http://www.betelarquitetura.com.br/seu-projeto-sustentavel/, 2017)

O telhado intensivo caracteriza-se pelo uso de plantas de médio a grande porte, como na figura 6, sendo considerado o tipo com maior peso sobre a estrutura pela necessidade de utilização de uma camada de substrato mais espessa por conta do porte das árvores. Por conta disso somente podem ser instalados em bases horizontais. A estrutura para esse tipo de telhado deve possuir de $15 \mathrm{~cm}$ a $40 \mathrm{~cm}$ e a carga prevista varia entre $180 \mathrm{~kg} / \mathrm{m}^{2}$ e $500 \mathrm{~kg} / \mathrm{m}^{2}$. É necessária uma manutenção de maios frequencia sendo recomendados cuidados mensalmente. 
FIGURA 6 - Cobertura verde intensiva sobre laje.

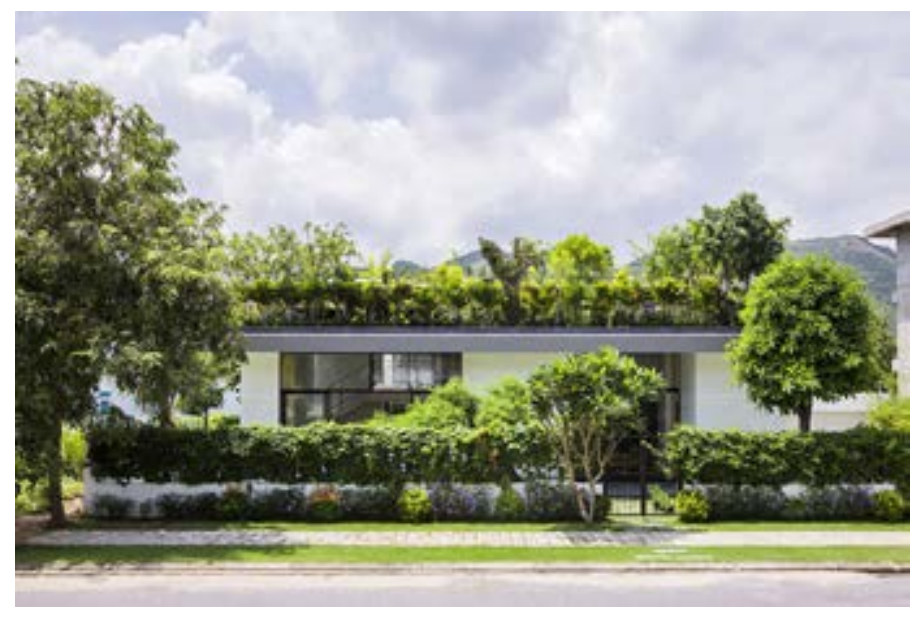

FONTE: (Reproduçao/ Vo Trong NGHIA Architects e ICADA - https://www.tuacasa.com. br/telhado-verde/, 2019)

O telhado semi-intensivo é considerado intermediário por conter vegetação de porte médio sobre uma estrutura de $12 \mathrm{~cm}$ a $25 \mathrm{~cm}$ podendo exercer uma carga de 120 $\mathrm{kg} / \mathrm{m}^{2}$ a $200 \mathrm{~kg} / \mathrm{m}^{2}$. Segundo (SILVA, 2016), a cobertura semi-intensiva tem a mesma filosofia do telhado extensivo, porém com a possibilidade de uma maior variedade de plantas abrangendo desde suculentas, musgos e gramíneas até pequenos arbustos por possuir camadas mais profundas de substratos. Requer uma maior manutenção e agrega maior peso a estrutura em relação ao telhado extensivo.

A tabela abaixo traz informações resumindo tais diferenças. 
TABELA 1 - Classificaçao de telhados verdes

\begin{tabular}{|c|c|c|c|}
\hline Itens & $\begin{array}{l}\text { Telhado Verde } \\
\text { Extensivo }\end{array}$ & $\begin{array}{l}\text { Telhado Verde } \\
\text { Semi-intensivo }\end{array}$ & $\begin{array}{l}\text { Telhado Verde } \\
\text { Intensivo }\end{array}$ \\
\hline Manutenção & Baixa & Periodicamente & Alta \\
\hline Irrigaçäo & Näก & Periodicamente & Regularmente \\
\hline Plantas & $\begin{array}{l}\text { Sedum, ervas } \theta \\
\text { gramineas. }\end{array}$ & $\begin{array}{l}\text { Gramado, ervas } \theta \\
\text { arbustos. }\end{array}$ & $\begin{array}{c}\text { Gramado, arbustos } \theta \\
\text { arvores. }\end{array}$ \\
\hline Altura do substrato & $6-20 \mathrm{~cm}$ & $12-25 \mathrm{~cm}$ & $15-40 \mathrm{~cm}$ \\
\hline Peso & $60-150 \mathrm{~kg} / \mathrm{m}^{2}$ & $120-200 \mathrm{~kg} / \mathrm{m}^{2}$ & $180-500 \mathrm{~kg} / \mathrm{m}^{2}$ \\
\hline Custo & Baixo & Médio & Alto \\
\hline Uso & Jardim, gramado & Jardim, parque & $\begin{array}{l}\text { Parque, arvores c } \\
\text { arbustos. }\end{array}$ \\
\hline
\end{tabular}

FONTE: (https://bioclimatismo.com.br/telhado-verde/, 2016)

\section{SISTEMAS DE APLICAÇÃO}

O telhado verde consiste em uma técnica arquitetônica que faz a aplicação e o uso do solo e vegetação em diversos tipos de edificações. De acordo com (FERREIRA, 2016), a instalação de um telhado verde pode ser realizada utilizando basicamente 3 diferentes sitemas de aplicação e construção.

\subsection{Aplicação Contínua}

Este é o sistema mais antigo e o mais difundido, na qual o substrato é aplicado diretamente sobre a base devidamente impermeabilizada e protegida por diferentes camadas.

Sua execução consiste em uma cobertura devidamente impermeabilizada, na qual geralmente são usadas mantas sintéticas afim de proteger a base de infiltrações, 
sendo que a estrutura da cobertura deve suportar o sistema dimensionado para ela, possuindo um ângulo de inclinação baixo ou nulo que determinarão a forma de drenagem ou a necessidade de barreiras para a contenção do fluxo de água.

Após esse processo é feita uma camada drenante onde poderá ser feita a utilização de diferentes materiais que sirvam para a drenagem e a filtragem da água como brita, argila expandida, seixos ou mantas drenantes de poliestireno.

Acima da camada drenante vem a camada filtrante com o uso de um geotêxtil e após essa camada utiliza-se uma membrana de proteção contra raízes que servem para o controle do crescimento delas. Por fim é colocada a camada de substrato e a vegetação adequada (FERREIRA, 2016). Na figura 7, um exemplo da disposição dos materiais nesse tipo de aplicação.

FIGURA 7 - Componentes do telhado verde.

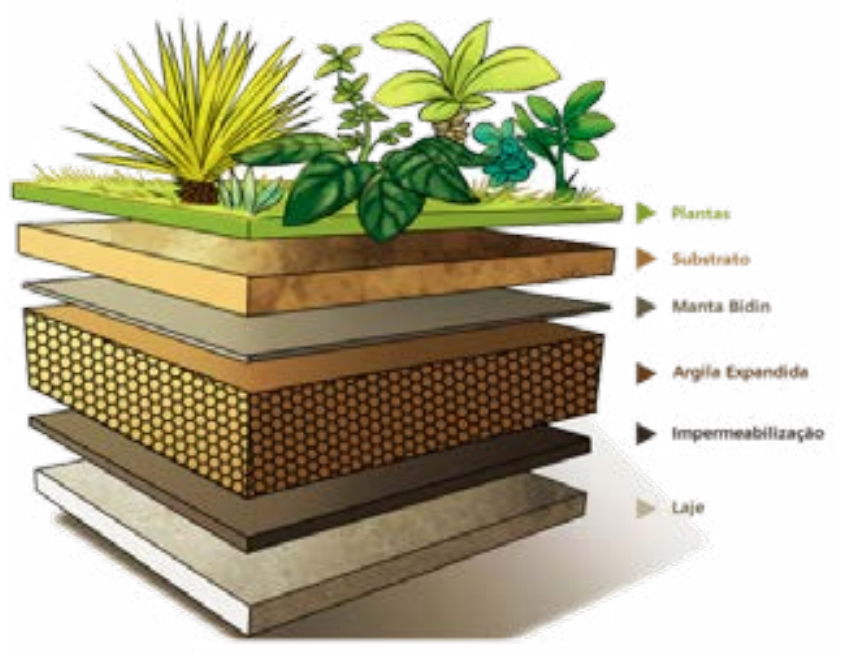

FONTE: (http://www.barearquitetura.com/por-que-e-como-fazer-um-telhado-verde/, 2016) 
Em regiões de clima frio, devera ser feita a utilização de uma camada que impeça a condensação de vapor de água em uma membrana isolante sob a camada de impermeabilização (PENDIUK, 2017).

\subsection{Aplicação a partir de módulos pré-elaborados}

Normalmente comercializado por empresas especializadas, o sistema modular consiste na utilização de bandejas rígidas com dimensões que facilitam o seu manuseio e colaboram para uma aplicação mais rápida e prática, como observado na figura 8, possuindo também uma fácil manutenção já que possibilita a retirada de uma bandeja por vez (FERREIRA, 2016).

Cada bandeja contém uma camada de substrato e a vegetação já crescida (figura 9), trazendo um resultado imediato e permite o cultivo de forrações, arbustos e hortaliças com porte de até $40 \mathrm{~cm}$ de altura, possibilitando também o plantio de diferentes tipos de vegetação por bandeja (PENDIUK, 2017).

Sua aplicação é feita diretamente sobre a base que pode ser plana ou inclinada. Para superfícies planas deve haver a utilização de impermeabilização e para superfícies inclinadas, que devem ter até $35^{\circ}$, a preocupação deve ser em relação aos beirais que devem ser reforçados para aguentar a pressão das bandejas, evitando o deslizamento dos módulos. 
FIGURA 8 - Aplicação de módulos pré-elaborados sobre laje impermeabilizada.

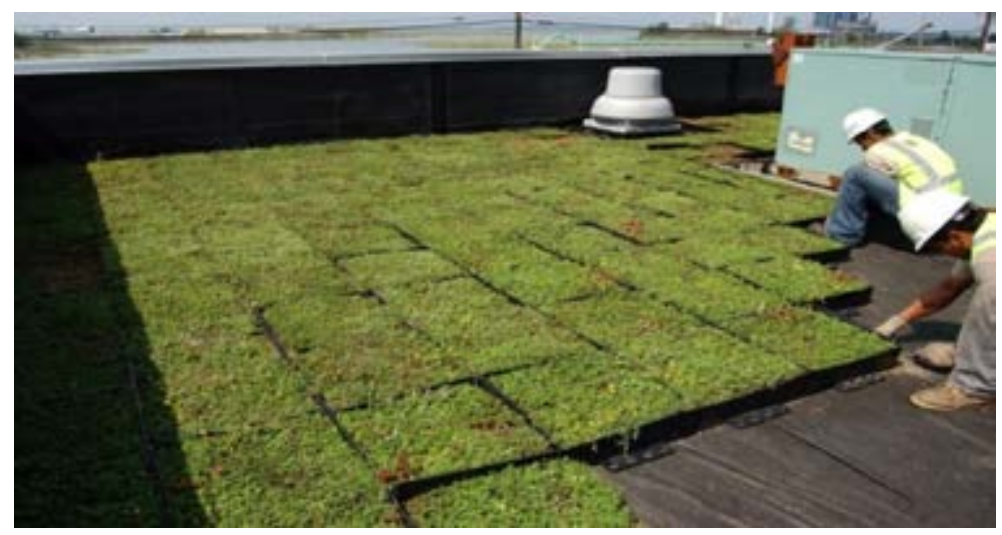

FONTE: (http://www.artevegetal.com.br/telhados-verdes/, 2017)

FIGURA 9 - Imagens de módulos pré-elaborados.

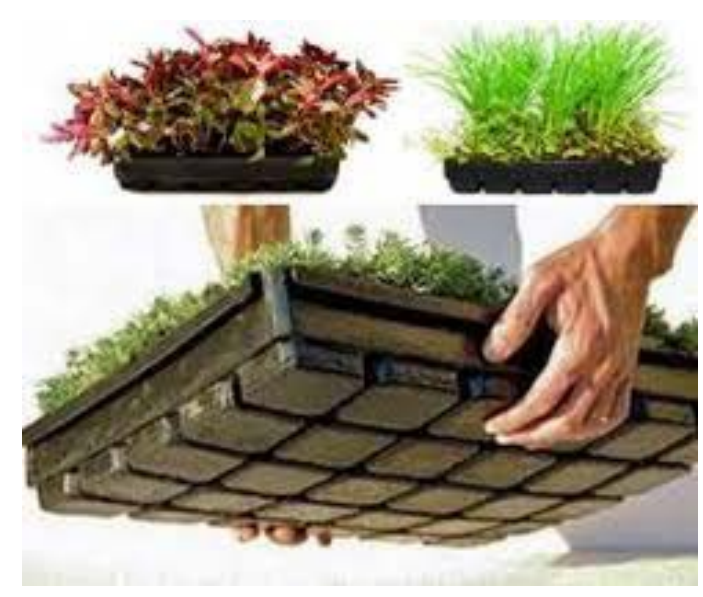

FONTE: (ARCOWEB, 2009)

Há também a possibilidade do emprego de pisos elevados para o armazenamento de águas das chuvas que poderá ser utilizada para a própria irrigação das plantas. 


\subsection{Aplicação aérea}

Diferentemente dos sistemas anteriores, esta solução pode ser tida como uma cobertura viva da cobertura tradicional, como visto na figura 10. Suas vantagens são em relação à estrutura pois seu peso não é colocado completamente sobre a cobertura, porém, por ser separada da base, não possui o mesmo efeito isolante das soluções anteriores. Nesse tipo de aplicação, podem ser utilizados diferentes tipos de materiais para a estrutura com a utilização de vegetação trepadeira, contribuindo para amenizar a temperatura, diminuir a incidência de iluminação e reduzir ruídos das chuvas sobre a cobertura (PENDIUK, 2017).

FIGURA 10 - Cobertura do Centro de Educação Permanente em Saúde Pública.

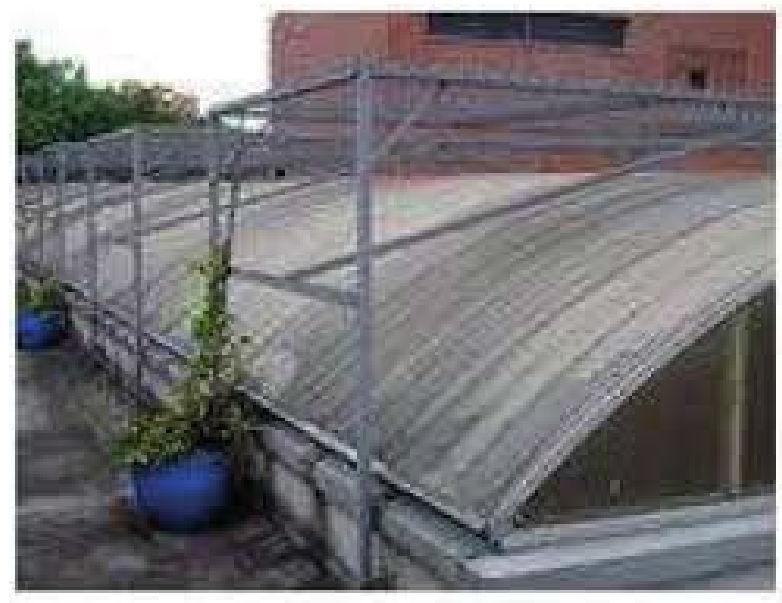

FONTE: (periodicos.set.edu.br)

\section{VANTAGENS}

Com os constantes problemas gerados pelo crescimento das áreas urbanas e a escassês de áreas verdes naturais, a demanda pelo uso de soluções que consigam mini- 
mizar parte dos impactos negativos provenientes do uso desenfreado de materiais que não contribuem para o meio ambiente e o bem estar de todos, a utilização das "coberturas vivas" tornou-se algo primordial para amenizar esses impactos e contribuir para a reintrodução de áreas verdes no espaço urbano afim de conviver mutuamente com a civilização sem gerar grandes desequilíbrios (MARINHO, 2018).

Os telhados verdes se tornaram um grande aliado principalmente contra o aquecimento global e quando construídos em larga escala contribuem com a arborização urbana (SAVI, 2018). Essas são apenas algumas das inúmeras vantagens que a utilização do telhado verde pode trazer tanto para os ambientes internos quanto para o meio ambiente e a sociedade.

Outras dessas vantagens são:

- Funciona como um isolante térmico e acústico, evitando a transferência de calor, visualizado na figura 11, frio ou ruído para o interior da edificação proporcionando um ambiente interno mais agradável e consequentemente reduzindo gastos energéticos com refrigeração ou aquecimento;

FIGURA 11 - Imagem em infravermelho de um telhado verde.

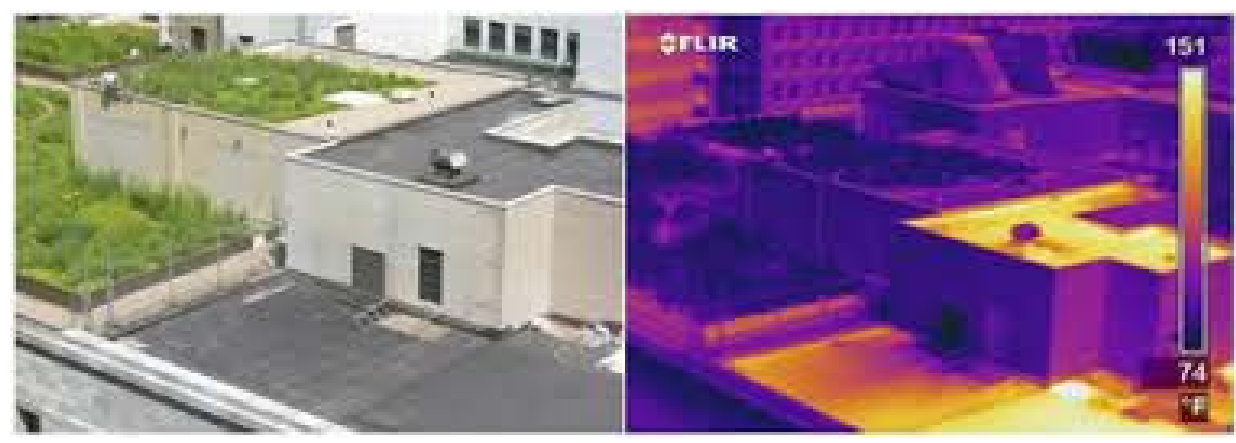

FONTE: (Center for Clean Air Policy, 2009)

- Em conjunto com ações que contribuam para a gestão das águas pluviais, auxilia na retenção de água das chuvas reduzindo inundações, com a diminuição do escoamento pela rede pública, córregos e rios; 
- Sua utilização em larga escala possibilita uma melhora na qualidade de vida nas áreas urbanas melhorando a qualidade do ar com a produção de oxigênio e pela captação de carbono e outros gases do efeito estufa decorrentes da poluição;

- Diminuição das ilhas de calor pela redução das superfícies pavimentadas e impermeáveis;

- Reequilíbrio ambiental com a utilização de plantas nativas, tornando-se habitat para insetos e pássaros;

- Evita o desgaste das coberturas protegendo-as de condições degradantes (intempéries, insolação, entre outros), aumentando a sua vida útil;

- Proteje contra incêndios pois retarda o alastramento das chamas;

- Aumento do espaço para lazer;

- Melhoria na qualidade de vida e na saúde física e mental, ao proporcionar um benefício estético interrompendo a monotonia dos centros urbanos;

- Produção de alimentos;

- Juntamente com a implantação de painéis solares podem reduzir ainda mais o consumo de energia elétrica.

- De forma geral, as coberturas verdes sao responsáveis por benefícios estéticos, terapêuticos, de lazer e social.

\section{DESVANTAGENS}

Apesar de haver poucas dificuldades na utilização de coberturas verdes, de acordo com (BRITO et al., 2018), há a necessidade de atenção principalmente em relação à sua implantação, levando em conta alguns aspectos citados a seguir:

- Alto investimento na implantação e manutenção comparados com os tipos de cobertura tradicionais, porém acaba se tornando lucrativo a longo 
prazo devido a economia de energia, de água e à vida mais longa das estruturas das edificações;

- Provável aumento de custo de algumas estruturas podendo haver a necessidade de reforço de alguma edificação já existente e para construções novas necessita-se cálculo estrutural que garanta a resistência da laje referentes ao acúmulo da água e ao peso total da cobertura verde;

- Pode haver restrições por parte do uso de alguma vegetação em relação à estrutura, à temperatura, dentre outras características ambientais que por fim podem inviabilizar o projeto;

- A complexidade do projeto de um telhado verde faz com que haja a necessidade de mão de obra especializada, com profissionais que garantam principalmente a segurança por envolver diversos aspectos de um imóvel;

- Dependendo do tipo de vegetação utilizada no telhado verde e não havendo uma manutenção adequada poderá resultar no surgimento de pragas tornando-o inviável. Um controle deverá ser realizado apenas se houver prejuízos ao jardim ou aos seus usuários, utilizando o mínimo de inseticidas evitando a má qualidade da água absorvida pelo sistema de reutilização e a poluição do solo.

\section{CUSTOS}

Não é possivel definir um valor exato para as coberturas verdes, pois depende dos detalhes de cada necessidade e situação. Porém, de forma geral, mesmo que sua implantação demande um certo custo, este valor poderá ser compensado pela sua eficiência a médio ou longo prazo na qual consideram-se seus benefícios como o conforto ambiental da edificação, a gestão das aguas pluviais, com a geração de alimentos, dentre outros.

Na verdade, há a necessidade de um maior incentivo e de uma maior informação quanto ao telhado verde pois ainda há uma idéia por parte da sociedade que sua uti- 
lização está ligada a degradação dos materiais pela presença de plantas, sendo que na realidade a estrutura se mantém preservada, duplicando sua vida útil evitando também gastos com a deterioração que uma cobertura normalmente teria em condições a que normalmente se encontram (COLLI, 2018).

\section{ESTUDOS RELACIONADOS AOS TELHADOS VERDES NO BRASIL}

Apesar de seu grande potencial, no Brasil, ainda é rara a implantação de coberturas verdes e são raros os estudos científicos em relação à sua implantação em regiões de climas tropicais. Há um maior conhecimento científico sobre o assunto em climas temperados e uma maior iniciativa principalmente na Europa e nos Estados Unidos da América, destaca (RANGEL, 2015), havendo uma maior seleção de espécies para essas localidades e suas determinadas caracteristicas para esses climas.

Com 19\% da flora total do planeta, no total de 56.000 espécies (SILVA, 2016), o Brasil detém uma rica fonte de biodiversidade vegetal para utilização em telhados verdes e possui um imenso potencial através da oportunidade de avaliação de espécies que poderiam e deveriam estar sendo reintroduzidas no nosso contexto urbano, havendo a utilização de espécies mais tolerantes ao clima extremo similar ao encontrado sobre as coberturas. 
GRÁFICO 1 - Comparação quantitativa de estudos realizados sobre telhado verde no Brasil (claro) e no exterior (escuro).

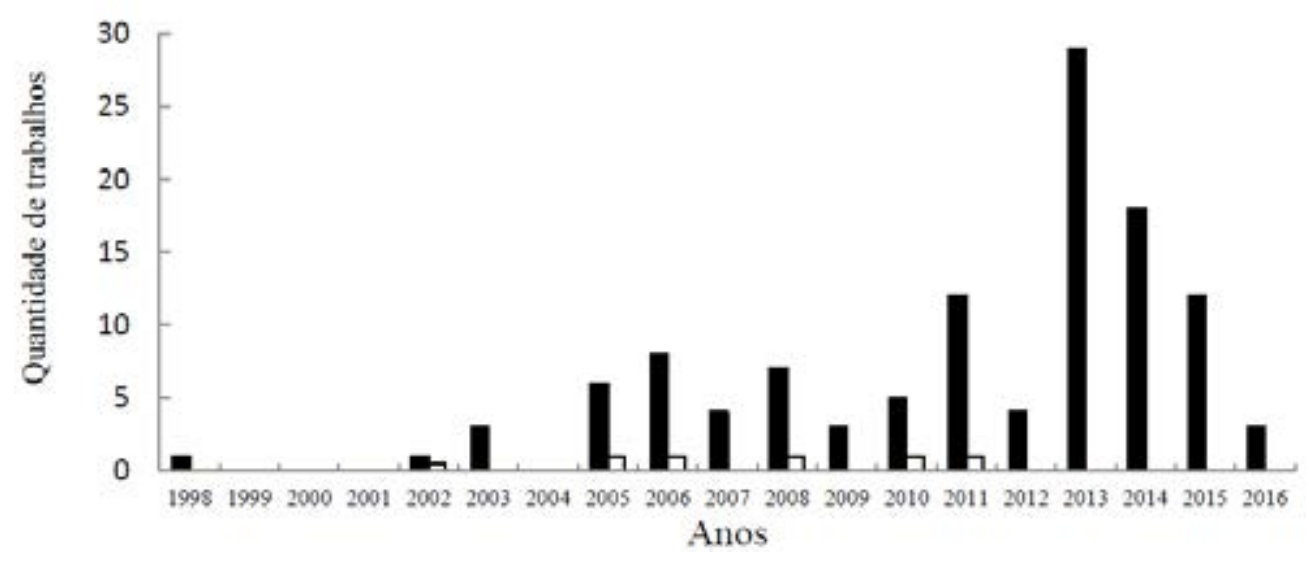

FONTE: (SILVA, 2016)

Portanto, por conta da falta de material científico e mesmo sendo uma alternativa viável e sustentável, esta solução ainda vem sendo pouco utilizada nas regiões de clima mais quente, sendo mais adotados em regiões onde o calor é mais ameno, como no Sul do país, até também pela menor manutenção que esse tipo de clima requer.

A implantação das coberturas verdes é parte fundamental como política social e ambiental, principalmente para moradias de baixa renda, onde encontra-se uma maior necessidade em ampliar essa utilização, pois são as regiões carentes as que mais sofrem com os efeitos relacionados principalmente ao aquecimento global (SILVA, 2018). Há também pouco incentivo por parte do governo, porém atualmente está havendo um esforço maior em reverter essa situação com a adoção, mesmo que timidamente, de alguns projetos de lei em alguns estados.

Os sistemas geralmente utilizados ainda não são considerados acessíveis a todos, pois são complexos, necessitando de diversos fatores para que se torne viável a sua implantação sem riscos de danos futuros, o que pode acabar tornando seu custo elevado.

Atualmente, no Brasil, necessita-se um maior investimento e incentivo na elaboração de estudos relacionados a novos tipos de sistemas de implantação de telhados verdes, principalmente que sejam mais baratos tornando-os acessíveis a todos (SETTA, 
2017). Existe também uma grande necessidade de conhecimento científico em relação ao uso de espécies da flora brasileira em coberturas verdes, o que acarreta na não sobrevivência de algumas plantas que comumente são utilizadas por nao suportarem altas temperatura, principalmente em épocas como no Verão.

Segundo (SILVA, 2016), para a realidade brasileira é necessária uma metodologia com mínima complexidade e baixo custo, utilizando flora local que se adapte às condições extremas do nosso clima e aos extremos abióticos e que consigam sobreviver nas condições estressantes das coberturas tropicais.

As coberturas verdes possuem uma grande vantagem em climas tropicais por não sofrerem riscos de congelamento, dentre outros fatores relacionados a outros climas. Outra vantagem é uma maior possibilidade de diversificadas espécies para serem utilizadas, havendo uma maior diversidade de projetos, mantendo uma identidade própria.

\section{CONSIDERAÇÕES FINAIS}

Diante do estudo realizado, constatou-se a efetividade e os benefícios que a implantação das coberturas verdes proporcionam ao bem estar de forma geral, e a importância da implementação desse sistema tanto para ambientes internos, quanto para uma contexto ainda mais amplo como no controle do aquecimento global. Com isso, destaca-se a necessidade de ampliar o interesse em estudos científicos, principalmente no Brasil, onde existe um grande potencial, ampliando a busca de novas tecnologias que visem uma maior possibilidade de projetos que proporcionem, em especial, a redução de custos para que possa se difundir muito mais essa idéia, beneficiando a todos.

\section{REFERÊNCIAS}

ALMEIDA , Samuel Pablo Costa de; BRITO, Gabriela Pedroza de; SANTOS, Sylvana Melo. Revisão Histórica dos Telhados Verdes: da Mesopotâmia aos dias atuais. Corrente, PI: Revista Brasileira de Meio Ambiente, 2018. 
BALDESSAR, Silvia Maria Nogueira. Telhado verde e sua contribuição na redução da vazão da água pluvial escoada. Monografia, Curitiba, PR. Abril, 2012. 125 f.

BÄR, Bruna Vogt; TAVARES, Sergio Fernando. Estudo da arte do comportamento hidrológico de telhados verdes no Brasil: uma revisão sistemática. Campinas, SP: PARC Pesq. em Arquit. e Constr., 2018.

BRASIL. Lei $\mathbf{n}^{\circ} \mathbf{1 4 . 2 4 3}$, de 11 de Dezembro de 2007. Dispõe sobre a implementação de sistemas de naturação através da criação de telhados verdes em espaços urbanos de Santa Catarina. Disponível em:

<http://leis.alesc.sc.gov.br/html/2007/14243_2007_Lei.html> Acesso em 10 Jun. 2019.

Projeto de Lei $\mathbf{n}^{\circ}$ 622, de 29 de Outubro de 2008. Dispõe sobre a concessão de isenção parcial de impostos predial e territorial urbano - IPTU - incidentes sobre imóveis que sejam construídos ou adaptados com as medidas de proteção ambiental que especifica, institui o programa "edificação ecológica", e dá outras providências. Disponível em:

<https://www.radarmunicipal.com.br/proposicoes/projeto-de-lei-622-2008> Acesso em 10 Jun. 2019.

. Lei $\mathrm{n}^{\circ} \mathbf{2 3 5}$, de 28 de Dezembro de 2012. Fica instituído no Município de Goiânia o Programa IPTU Verde, com o objetivo de fomentar as ações que promovam o ideário de Cidade Sustentável, visando melhora na qualidade de vida dos habitantes, minimizar os impactos ao meio natural, eficiente desempenho urbanístico e motivação de êxito tributário com a participação cidadã, por meio de concessão de benefícios tributários. Disponível em:

<https://www.goiania.go.gov.br/html/gabinete_civil/sileg/dados/legis/2012/ Ic_20121228_000000235.html> Acesso em 10 Jun. 2019.

. Lei no 6.349, de 30 de Novembro de 2012. Dispõe sobre a obrigatoriedade da instalação do "telhado verde" nos locais que especifica e dá outras providências. Di- 
sponível em:

<https://gov-rj.jusbrasil.com.br/legislacao/1033548/lei-6349-12> Acesso em 10 Jun. 2019.

. Lei no 18.112, de 12 de Janeiro de 2015. Dispõe sobre a melhoria da qualidade ambiental das edificações por meio da obrigatoriedade de instalação do "telhado verde", e construção de reservatórios de acúmulo ou de retardo do escoamento das águas pluviais para a rede de drenagem e dá outras providências. Disponível em:

<https://www.legisweb.com.br/legislacao/?id=280138> Acesso em 10 Jun. 2019.

Decreto no 29.100, de 06 de Novembro de 2017. Regulamenta o art. 5o da Lei no 8.474, de 02 de outubro de 2013, e institui o Programa de Certificação Sustentável "IPTU VERDE" em edificações no Município de Salvador, que estabelece benefícios fiscais aos participantes do programa, assim como o art. 5o da Lei 8.723 de 22 de dezembro de 2014 e dá outras providências. Disponível em:

<https://www.legisweb.com.br/legislacao/?id=352266> Acesso em 10 Jun. 2019.

BRASIL, Matheus Paiva; BARRETO, Felipe Ataíde. Aspectos construtivos e ambientais de telhados verdes extensivos. Salvador, BA: I COBESA, 2010.

BRITO, Mayara de et al. A implantação do telhado verde e sua efetividade no meio urbano. 6o Simpósio de Sustentabilidade, 2018.

COLLI, Felipe Rodrigues et al. Análise e percepções dos profissionais de engenharia civil na aplicação do sistema de Coberturas verdes. Anais da Engenharia Civil / 25951823, [S.I.], v. 1, n. 1, p. 77 - 96, apr. 2018.

CORRENT, Luan; LEHMANN, Priscila. Telhado verde: da Babilônia aos dias atuais. Fortaleza: Revista Científica Semana Acadêmica, 2017. 
FERREIRA, Manoela de Freitas. Teto verde: o uso de coberturas vegetais em edificações. Rio de Janeiro: Departamento de Artes \& Design, 2016.

GARGARI, Caterina et al. Environmental impact of Green roofing: the contribute of a green roof to the sustainable use of natural resources in a life cycle approach. Italia: ScienceDirect, 2016.

HENN, Ana Bell; CAGLIARI, Aléssio Inácio. A aplicabilidade do telhado verde em centros urbanos. Santa Catarina: IMED, 2016.

HENN, Ana Bell; CAGLIARI, Aléssio Inácio. A implantação do telhado verde e sua efetividade. Santa Catarina: IMED, 2016.

IGRA - International Green Roof Association. Disponível em: http://www.igra-world. com/. Acesso em: 10/jun/2019.

JUNIOR, Alfredo Akira Ohnuma; MARQUES, Marcia; SILVA, Luciene Pimentel da. Efeitos globais da temperatura e da precipitação em telhados verdes. Rio de Janeiro: UFPR, 2017.

JUNIOR, Alfredo Akira Ohnuma; SILVA, Luciene Pimentel da; GOMES, Marcia Marques. O efeito das condições climáticas em telhados verdes. Distrito Federal: ABRH, 2015.

LI, W.C. ; YEUNG, K.K.A. A comprehensive study of green roof performance from environmental perspective. Hong Kong: ScienceDirect, 2014.

MARINHO, Haiany Martins; ASSIS, Miguel Martins de. Estudo de caso: vantagens e desvantagens da implantação de telhado verde. Ponta Grossa, PR: ConBRepro, 2018.

MUÑOZ, Juan Sebastián Carvajal; GARCIA, Charlie Esperanza Carmona. Global re- 
search trends in green roofs: benefits, main developments and future needs. Colombia: Scielo, 2015.

OLIVEIRA, Patrícia Lima de; SOARES, Raquel Gomes; SANTOS, Silvio Xavier. Desempenho térmico das edificações: estudo comparativo entre o telhado verde e outros tipos de coberturas. Belo Horizonte, MG: Revista Petra, 2016.

PENDIUK, Fábio; MOISES, Izabela Cristina; PEREIRA, Matheus Pedron. Telhado verde: a evolução da tecnologia e suas funcionalidades. Paraná: Gest. Tecnol. Inov. Vol.01 n.3, 2017.

POOROVA, Zuzana et al. Importance of Different Vegetation Used on Green Roofs in Terms of Lowering Temperature and Water Retention. Slovakia: ScienceDirect, 2016.

RAHMAN,Syumi Rafida Abdul et al. Perception of Green Roof as a Tool for Urban Regeneration in a Commercial Environment: The Secret Garden, Malaysia. Malaysia: ScienceDirect, 2015.

RANGEL, Ana Celecina Lucena da Costa; ARANHA, Kaline Cunha; SILVA, Maria Cristina Basílio Crispim da. Os telhados verdes nas políticas ambientais como medida indutora para a sustentabilidade. Curitiba, PR: SER/ UFPR, 2015.

SANTOS, Leonildo Rasec Lima dos et al. Tehado verde: Uma proposta sustentável para a construção civil. Alagoas: Cadernos de Graduação, 2017.

SANTOS, Pedro Tyaquiçã da Silva et al. Telhado verde: desempenho do sistema construtivo na redução do escoamento superficial. Porto Alegre, RS: Scielo, 2013.

SAVI, Adriane Cordoni; TAVARES, Sergio Fernando. Telhados verdes: uma análise da influência das espécies vegetais na retenção de água de chuva. Passo Fundo, MG: IMED, 2018. 
SEMAAN, Mary; PEARCE, Annie. Assessment of the Gains and Benefits of Green Roofs in Different Climates. Blacksburg VA: ScienceDirect, 2016.

SETTA, Bruno Rocha Silva. Telhados verdes como políticas públicas ambientais para o município de Volta Redonda - RJ. Rio de Janeiro: Revista LABVERDE, 2017.

SILVA, Bruno Rezende. Telhados verdes em clima tropical: uma nova técnica e seu potencial de atenuaçao térmica. Monografia, Rio de Janeiro, Julho de 2016.

SILVA, Isis Arend da et al. Tecnologia "telhado vivo": Estudo e potencial de integração de plantas nativas na cobertura e resgate da fauna. Curitiba, PR: SER/ UFPR, 2014.

SILVA, Vinicius Luis Arcangelo; KASHIWA, Larissa. Sustentabilidade e conforto: A aplicação do telhado verde como solução sustentável. Florianopolis, SC: Mix Sustentável, 2018.

VIEIRA, Thomas Jeferson; FLEISCHFRESSER, Luciano; PRUDENTE, Lucas Augusto. Comparação da variação de temperatura interna de um ambiente revestido com telhado verde e um com telhado convencional. São Paulo: Blucher, 2016.

VISENTIN,Tales Gonçalves; NECKEL, Alcindo; BREDA, Anaise. Telhados verdes como um meio sustentável nas cidades: Propostas recicláveis de produção. Porto Alegre, RS: IBEAS, 2015. 